\title{
Comparison of Biot-Savart's Law and 3D FEM in the Study of Elec- tromagnetic Forces Acting on End Winding
}

\author{
Ki-Chan $\operatorname{Kim}^{\dagger}$
}

\begin{abstract}
An induction motor operated with high voltage source generally generates high current in starting mode and has a long transient time after being started. This large and sustaining starting current causes the end windings of the stator to have excessive electromagnetic force. This force is the source of vibration and has a negative and serious influence on the insulation of end windings. Therefore, designing the end winding part with an appropriate support system is needed. To design the support ring enclosing the end windings, we analyze the distribution of electromagnetic force on the end windings by applying the Biot-Savart's law and the 3D finite element method (FEM), and comparing two simulation methods. Finally, we verify the safety of the support structure of the end winding part using stress analysis, which is analyzed with the electromagnetic forces from the 3D FEM simulation.
\end{abstract}

Keywords: Biot-Savart's law, End winding of stator, Electromagnetic force distribution, 3D finite element method

\section{Introduction}

Designing with high power density is currently needed for electrical rotating machines such as motors and generators. The rotating machine is designed with high fill factor of windings and compact size. In designing a high-power induction motor, the electromagnetic force acting on the end windings of a stator becomes increasingly severe because of high current density in a coil. There are also many problems related to the fault of the winding insulation due to stress and vibration, among other factors. The distribution of electromagnetic force on end windings should be considered and analyzed accurately before manufacturing.

To date, several approaches for calculating the distribution of the end winding force have been proposed [1]-[5]. There is a difference between the calculated force and the real force. In 1988, Williamson and Ellis presented a method for calculating the end winding force considering the rotor current distribution of induction motor using Biot-Savart's law [6]. However, a limitation of BiotSavart's law is that it is applicable only to free space; that is, magnetic fields near the ferromagnetic material in the vicinity of the end winding have significant errors between the measured force and the calculated force. Khan, Buckley, and Brooks used quasi 3D finite element method (FEM) in 1989 [7]. However, quasi 3D FEM is very complicated to program and assessing the magnetic flux variation in the peripheral direction is difficult. Furthermore, considering the effect of a teeth structure of the core is impossible.

In the current study, we calculate the distribution of elec-

\footnotetext{
$\bar{\dagger}$ Corresponding author: Department of Electrical Engineering, Hanbat National University, Korea. (kckim@hanbat.ac.kr) Received: August 24, 2010; Accepted: March 2, 2011
}

tromagnetic force acting on end windings of a high-power induction motor by using two calculation methods. One is Biot-Savart's law and the other is 3D FEM. The latter can analyze end winding forces more precisely than the former. As an application of the force calculation results, we can conduct a stress analysis of the end windings by inputting the force distribution already calculated by 3D FEM. Finally, we design the support ring surrounding the end windings to prevent the fault of winding insulation by stress caused by electromagnetic forces. The proposed method can be widely applied to enhance the reliability of electrical machines in the future.

\section{Analysis of End Winding Force}

The high voltage induction motor generally generates a high starting current with considerably long transient time. The starting current causes end windings to have excessive electromagnetic force. Therefore, the calculation method for end winding forces is needed in the design stage.

\subsection{Biot-Savart's Law}

Biot-Savart's law is one of the electromagnetic force calculation methods between two conductors that are short, straight, and have a current. We can calculate the force distribution of end windings with any complex structure in free space. Free space means there is no magnetic material in the region.

In this paper, each coil of end windings is replaced by an equivalent filamentary conductor carrying the equal ampere-turn. The electromagnetic force between the filamen- 
tary conductors is also calculated. This method has an advantage because it is readily applicable to any structure of the end winding, any connection of the stator winding, and any current condition. This method is conceptually simple and relatively straightforward to use.

In Fig. 1, the elementary force that acts on the element $a$ carrying current $i_{a}(t)$ due to the current $i_{b}(t)$ in the element $b$ can be calculated by

$$
\overrightarrow{F_{e}}(t)=i_{a}(t) i_{b}(t) \frac{1}{|\vec{r}|^{3}} \vec{a} \times \vec{b}(\times \vec{r}) 10^{-7}[N]
$$

In the above equation, $\vec{r}$ is the position vector from the center of the element $b$ to the center of the element $a$. The electromagnetic force per unit length is (2), and the coefficient of the elementary magnetic force is (3).

$$
\overrightarrow{f_{e}}(t)=\frac{\overrightarrow{F_{e}}(t)}{|\vec{a}|}=\vec{k}_{e} i_{a}(t) i_{b}(t) \quad[N / \mathrm{cm}] .
$$

Note that $k_{e}$ is the coefficient of the elementary magnetic force.

$$
\overrightarrow{k_{e}}=\frac{0.1}{|\vec{a}||\vec{r}|^{3}}[(\vec{a} \cdot \vec{r}) \vec{b}-(\vec{a} \cdot \vec{b}) \vec{r}]
$$

where

$\vec{a}=\vec{a}(m, n) \quad: \mathrm{m}$-th element of the $\mathrm{n}$-th coil

$\vec{b}=\vec{b}(\mu, \nu) \quad: \mu$-th element of the $v$-th coil.

$$
k_{e}=k_{e}(m, n, \mu, v)
$$

The electromagnetic force on the element $a(m, n)$ is computed by vector addition of elementary forces between the element $a$ and all the other winding elements. This

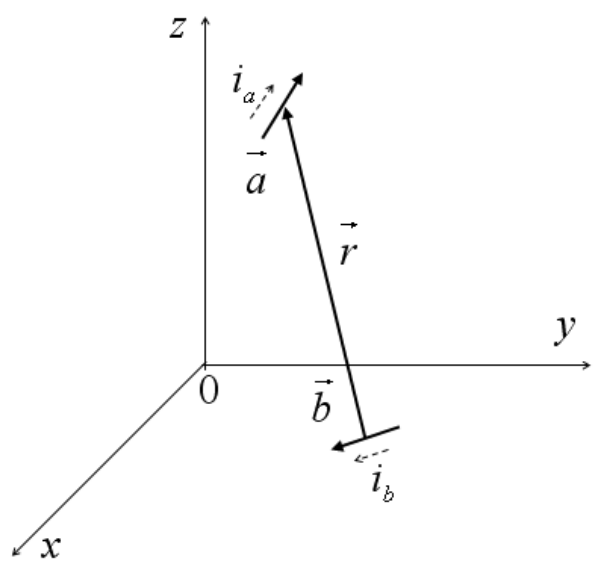

Fig. 1. Vector expression of two conductor segments method has an advantage because it integrates the forcecoefficients instead of the forces. For a more detailed explanation related to the calculation algorithm, refer to [8].

\subsection{D FEM Analysis}

The 3D FEM is capable of representing a complex geometry accurately and giving a more exact solution for the electromagnetic field even in the vicinity of the end core region, including slots and tooth structure.

Table. 1. Specifications of the Analysis Model

\begin{tabular}{l|c|c}
\hline \multicolumn{1}{c|}{ Item } & Unit & Specification \\
\hline Power & $\mathrm{kW}$ & 900 \\
Rated Voltage & $\mathrm{V}$ & 6,600 \\
Number of Pole & & 4 \\
Connection Type & & $\mathrm{Y}$ \\
Coil Pitch & & 10 \\
Number of Stator Slot/Rotor Slot & & $48 / 36$ \\
Silicon Steel Grade & $\mathrm{S} 23$ \\
Starting Current/Rated Current & $\mathrm{A}$ & $623 / 95$ \\
Diameter of Support Ring & $\mathrm{mm}$ & 10 \\
Material of Support Ring & & Polyglass \\
\hline
\end{tabular}

The specification of the analysis model with a squaretype armature winding is shown in Table 1 . The starting current of the motor is 6.56 times as high as the rated current, and takes $8 \mathrm{~s}$ from start to rated speed. The end winding force due to the large starting current affects the insulation material of end winding [9].

The end winding model with core and requirements for the pre-processor for 3D FEM is shown in Fig. 2. To save the calculating time, one pole model with half periodic boundary conditions (magnetic field intensity $H$ at master boundary plane and $-H$ at slave boundary plane) is used. In this case, the number of slots per pole per phase is four. The end core, rotor bar, and end ring are included in the model for the purpose of magnetic flux considering the end core and the end ring current. For simple analysis, we assume that the sinusoidal current is flowing in the stator winding. The end winding force at the start is calculated at the time when the starting current of the phase $\mathrm{A}$ is $\sqrt{2}$ times of the rms value, whereas the end winding force of phases $\mathrm{B}$ and $\mathrm{C}$ is the half and negative value of phase $\mathrm{A}$ current, respectively. In this model, the number of tetrahedral elements amounts to 234,563 .

In order to calculate the distribution of an end winding force, we segment a winding with 39 parts as shown in Fig. 3. We calculate the force caused by the current of each segment and the magnetic flux density at each segment. We consider the distribution of the end ring current by 2D transient FE analysis as well as three-phase current in a stator winding. After calculating the force on each part of a winding, the distribution result of an end winding is obtained. Therefore, 12 repetitive calculations generate the whole electromagnetic force distribution at the entire end windings. 


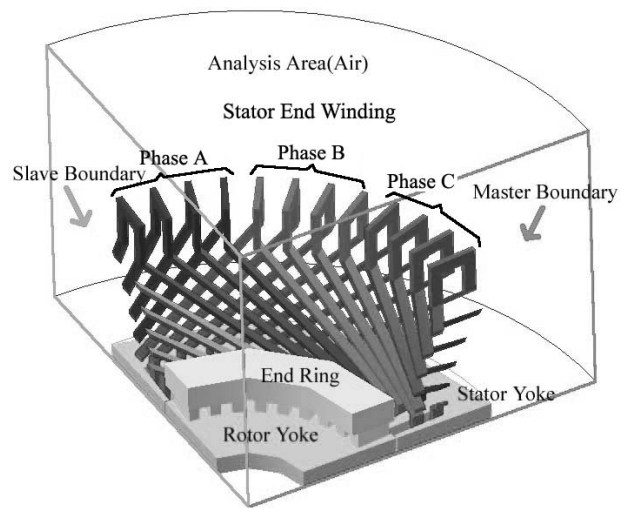

Fig. 2. 3D FEM analysis model with one pole and boundary condition.

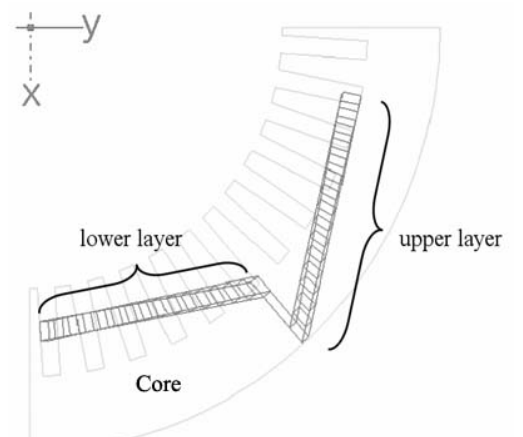

(a) Reference winding ( $x-y$ plane)

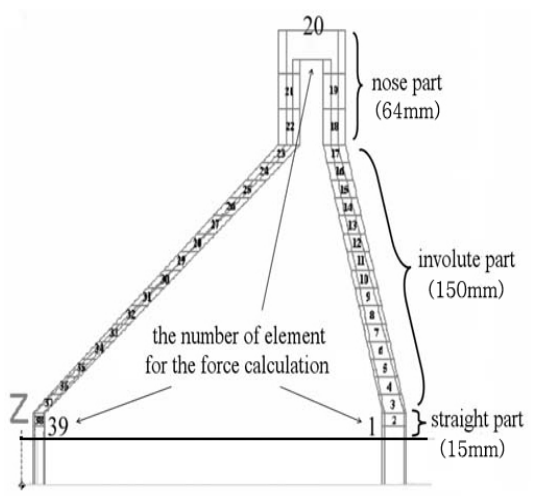

(b) The coil segment number (x-z plane)

Fig. 3. Definition of the reference winding for force calculation

\section{Comparison of End Winding Forces}

To compare the calculation results obtained by applying Biot-Savart's law with those by 3D FEM, we select the $4^{\text {th }}$ winding of A phase which is in the vicinity of the $1^{\text {st }}$ winding of $\mathrm{B}$ phase as a sample. The maximum electromagnetic force occurs at the $4^{\text {th }}$ winding of the A phase. The results obtained by applying 3D FEM in Fig. 4 show that segment numbers 1 and 2 of the upper layer coil and segment num-

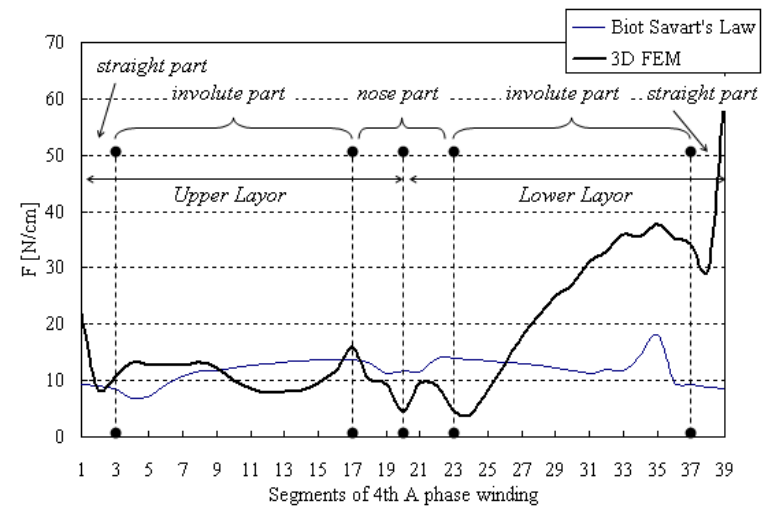

Fig. 4. Comparison of force calculation results by applying Biot-Savart's law and 3D FEM.

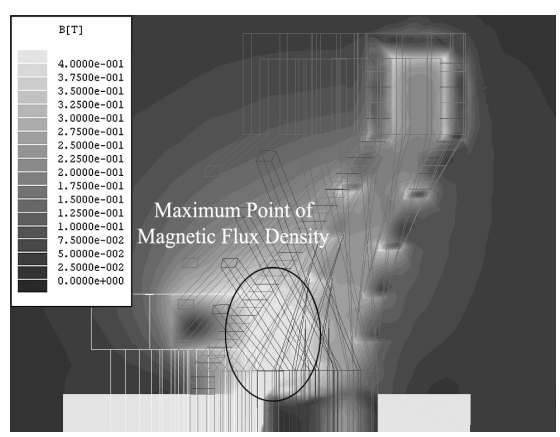

(a) x-z plane

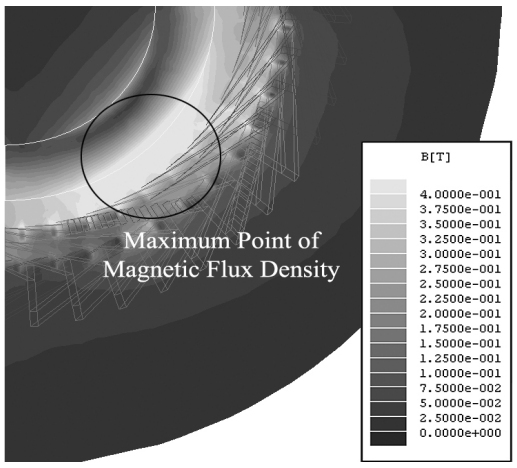

(b) $x-y$ plane

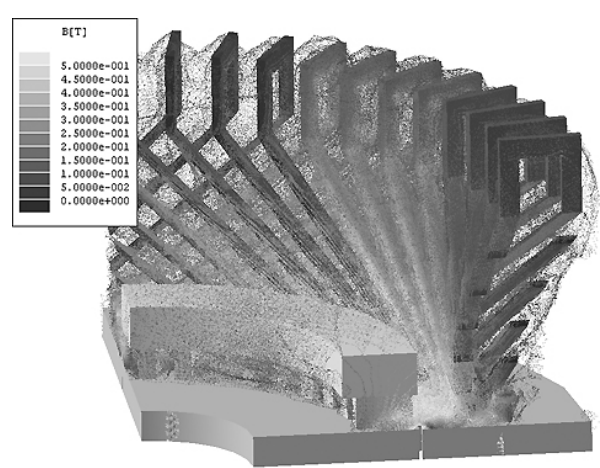

(c) $x-y-z$ space

Fig. 5. The results of the magnetic field of the end winding region 
bers 38 and 39 of the lower layer coil, which are both near the core in Fig. 3, have larger forces than the others due to their high flux density at the core. However, it is impossible to consider the effect of ferromagnetic material by applying Biot-Savart's law. Therefore, the two results have a high level of discrepancy. In conclusion, although the electromagnetic force by Biot-Savart's law is somewhat significant at the region of air, this force cannot be used at the region adjacent to the end core.

Fig. 5 shows the analysis of the magnetic field, including the leakage flux by 3D FEM. In this figure, we can verify that the leakage flux is generated high at the straight part of end winding in the vicinity of the core, at A phase windings which have maximum current, and at the lower part instead

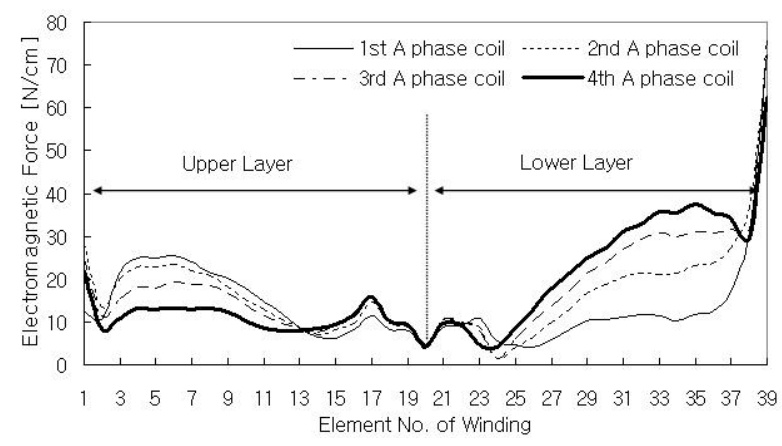

(a) The electromagnetic forces of the A phase group coils

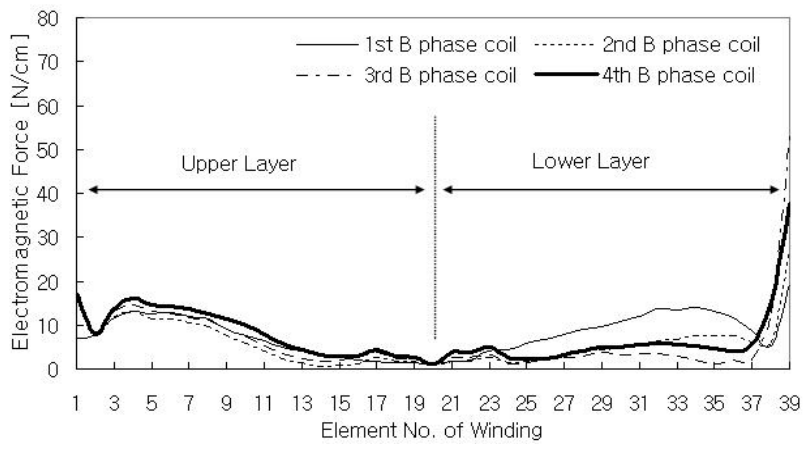

(b) The electromagnetic forces of the B phase group coils

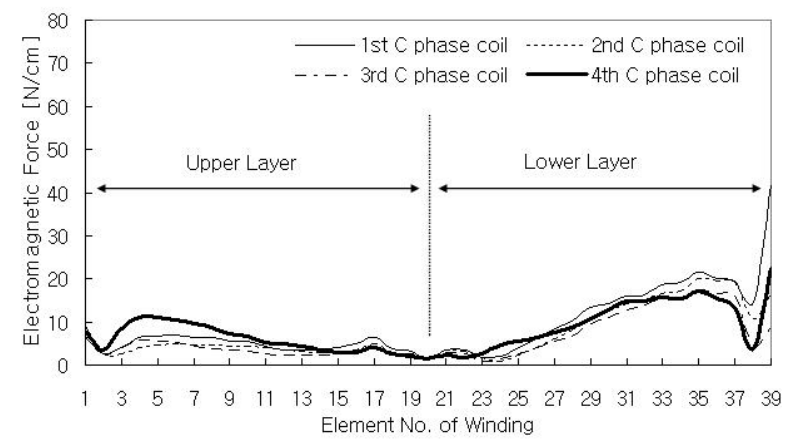

(c) The electromagnetic forces of the $\mathrm{C}$ phase group coils

Fig. 6. The electromagnetic forces distribution of end windings of the upper part.

Similar to the distribution of the magnetic flux, the electromagnetic force at the straight part, lower layer, and maximum current carrying the conductor is the largest, as shown in Fig. 6. There is a difference in force distribution even on the same phase windings having the same current. Fig. 7 shows the force vector on an $x-y$ domain of the straight and involute part of winding a pole. All the forces act in a radial outward direction. Therefore, the support ring surrounding the end windings is needed to prevent divergence of end windings.

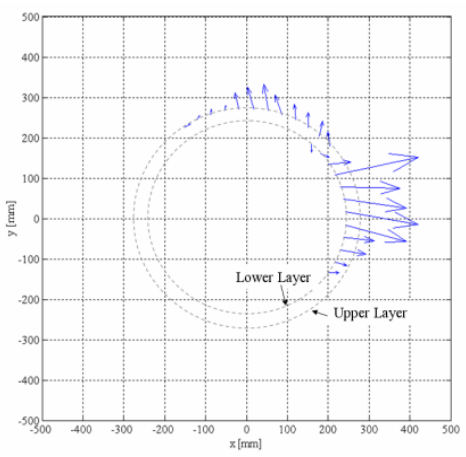

(a) Straight part of windings

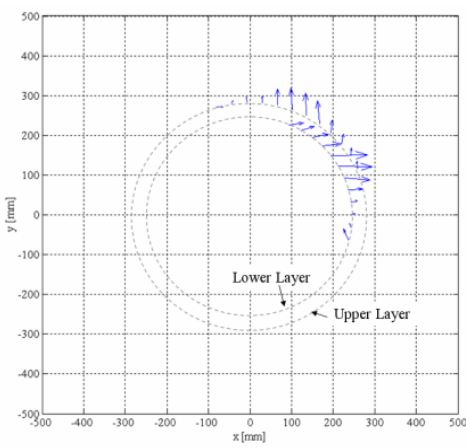

(b) Involute part of windings

Fig. 7. Vector distribution of electromagnetic force on three phase windings

\section{Reliability of the End Winding Insulation based on the Support Ring Design}

The stress analysis of an end winding with a supporting ring is conducted by inputting the distribution of electromagnetic force and comparing it with the yield stress of the support ring to ascertain the reliability of the support structure at the end winding of the induction motor. Fig. 8 shows the stress analysis result. We can verify the location of the maximum stress point. The insulation stability of end windings is also investigated by comparing the simulated maximum stress with the stress value at the insulation fault from a bending moment test. The properties and mechanical characteristics of the end winding part are in Table II. 
The stress analysis results are listed in Table III. The maximum stress of end winding is $21.94[\mathrm{MPa}]$. The maximum stress of a support ring is 3.8 [MPa]. As the maximum stress ratio is $0.318(=21.94 / 69)$, the design of end winding is within the very reliable level in comparison with the yield stress.

Finally, we calculate the stress ratio according to the displacement of the support ring. Fig. 9 shows the analysis model with the support ring. We can observe that the stress ratio decreased as the position of the support ring became more distant from the core part, as shown in Table IV.

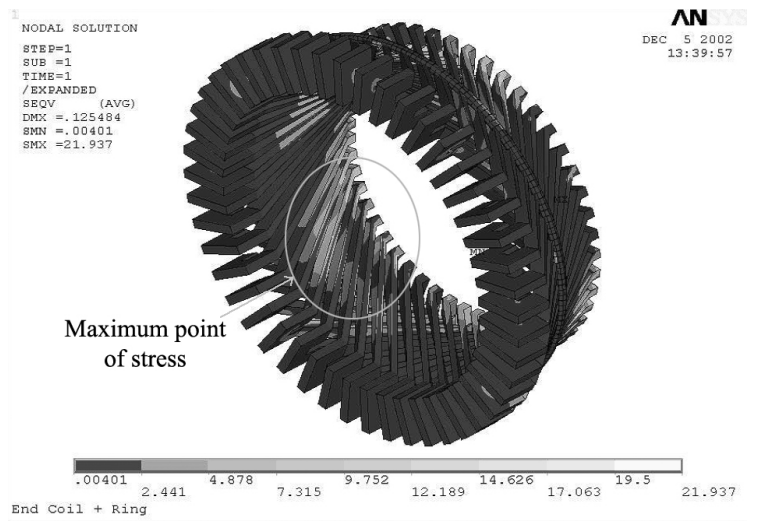

Fig. 8. The result of the stress analysis of end winding with the support ring

Table 2. Properties of Materials

\begin{tabular}{c|c|c|c}
\hline Section part & Conductor & Support ring & Insulator \\
\hline Material & Copper & Polyglass & Mica glass \\
Yield Stress. (MPa) & $\mathbf{6 9 - 3 5 0}$ & - & - \\
Tensile Stress (MPa) & - & 900 & 65 \\
\hline
\end{tabular}

Table 3. Results of Stress Analysis

\begin{tabular}{c|c|c|c|c}
\hline Section & $\begin{array}{c}\text { Coil } \\
\text { number }\end{array}$ & $\begin{array}{c}\text { Radial Displace- } \\
\text { ment }(\mathrm{mm})\end{array}$ & $\begin{array}{c}\text { Stress } \\
(\mathrm{MPa})\end{array}$ & $\begin{array}{c}\text { Stress } \\
\text { ratio }\end{array}$ \\
\hline & 1 & 0.071 & 10.13 & 0.147 \\
U phase Coil & 2 & 0.098 & 12.78 & 0.185 \\
& 3 & 0.106 & 17.89 & 0.259 \\
& 4 & 0.096 & $\mathbf{2 1 . 9 4}$ & 0.318 \\
\hline Support ring & - & 0.03 & 3.8 & 0.055 \\
\hline
\end{tabular}

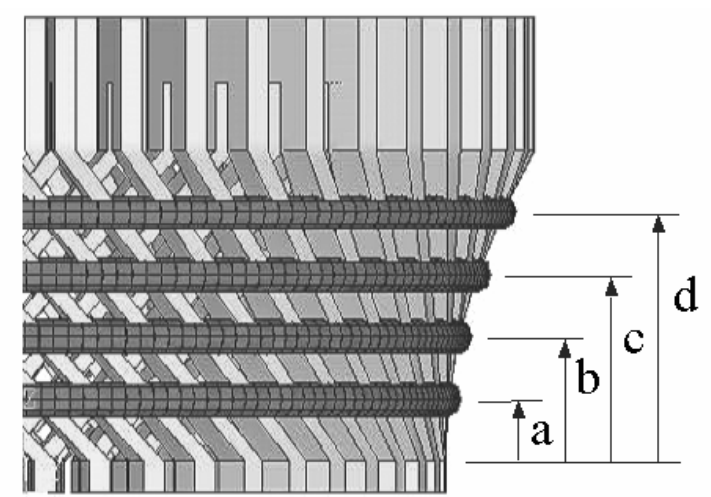

Fig. 9. The position of the supporting ring (a is $20 \%$ of the involute part, $\mathrm{b}$ is $40 \%$, c is $60 \%$, and $\mathrm{d}$ is $80 \%$ )
Table 4. The stress ratio based on the positions of the support ring

\begin{tabular}{c|c|c|c}
\hline Position & $\begin{array}{c}\text { Displacement } \\
(\mathrm{mm})\end{array}$ & Stress (MPa) & Stress ratio \\
\hline None & 0.144 & 23.89 & 0.346 \\
$20 \%$ & 0.14 & 23.58 & 0.342 \\
$40 \%$ & 0.125 & 22.77 & 0.33 \\
$60 \%$ & 0.102 & 21.77 & 0.316 \\
$80 \%$ & 0.076 & 20.86 & 0.302 \\
\hline
\end{tabular}

\section{Conclusion}

In this paper, two kinds of calculation methods for the distribution of end winding force were presented. We calculated the magnetic field and electromagnetic force of the end winding part of the high-power induction motor by applying Biot-Savart's law and 3D FEM. The distribution results of the electromagnetic forces using the two methods were compared, and 3D FEM was found to be a good method that precisely analyzes end winding forces. However, the calculation method using Biot-Savart's law has some validity at the region apart from the core and end ring. We also conducted a stress analysis of end windings by inputting the force distribution calculated by 3D FEM for the electromagnetic field. Finally, the reliability of the support ring in reducing the stress of end windings and in preventing insulation fault was verified by comparing the calculated stress with the yield stress of the support ring material.

\section{Acknowledgements}

This research was supported by the Basic Science Research Program through the National Research Foundation of Korea (NRF) funded by the Ministry of Education, Science and Technology (2010-0016727)

\section{References}

[1] D. Harrington, "Forces in Machine End Windings," AIEE Oct. 1952, pp 849-859.

[2] D. S. Ashworth and P. Hammond, "The Calculation of the Magnetic Field of Rotating Machines, Part 2 the Field of Turbo-Generator End-Windings," IEE No. 3489 S, Mar. 1961, pp 527-538.

[3] P. J. Lawrenson, "Forces on Turbo Generator End Windings," Proc. IEE, Vol. 112, No. 6, Jun. 1965, pp 1144-1158.

[4] T. Nomura, "Magnetic Forces Working on End Windings of Generators," Mitsubishi Technical Report Vol. 46, No. 10, 1972, pp 1129-1134.

[5] M. Ohtaguro, K. Yagiuchi, H. Yamaguchi, "Mechanical Behavior of Stator End Windings," IEEE Trans. Power Apparatus and Systems, Vol. PAS-99, 
No. 3, May/June 1980, pp 1181-1185.

[6] S. Williamson, M. R. E. Ellis, "Influence of Rotor Currents on End-Winding Forces in Cage Motor," IEE Proc. Vol. 135, Pt B, No. 6, Nov. 1988, pp 371379.

[7] G. K. M. Khan, G. W. Buckley, and N. Brooks, "Calculation of Forces and Stresses on Generator EndWindings Part I: Forces," IEEE Trans. Energy Conversion, Vol. 4, No. 4, Dec. 1989.

[8] X. Wen, R. Yao, J. A. Tegopoulos, "Calculation of Forces on the Stator End Windings of Turbo Generator by the Transient Quasi-3D Method," IEEE Trans. Magn., Vol. 32, No. 3, May 1996, pp 1669-1672.

[9] P. C. Krause, Analysis of Electric Machinery, McGraw-Hill, 1987.

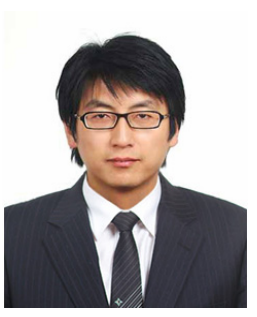

Ki-Chan Kim was born in Korea on August 8, 1972. He received his B.S., M.S., and Ph.D. degrees in Electrical Engineering from Hanyang University, Seoul, Korea in 1996, 1998, and 2005, respectively. He worked for Hyundai Heavy Industries Co., Ltd. (19982005). Currently, he is an Assistant Professor in Electrical Engineering at Hanbat National University, Daejeon, Korea. His special area of interest includes design and analysis of electrical rotating machine and sensors for electric vehicle. 